\title{
Partial upper median sternotomy for anterior aortopexy for innominate artery compression syndrome: Our preferred technique.
}

\author{
Sandeep Sainathan ${ }^{1}$ and Raghav Murthy ${ }^{2}$ \\ ${ }^{1}$ University of Miami Department of Surgery \\ ${ }^{2}$ Icahn School of Medicine at Mount Sinai Department of Cardiovascular Surgery
}

November 30, 2021

\begin{abstract}
Objectives: Innominate artery compression syndrome (IAS) is caused by an anterior compression of the trachea by an abnormally originating innominate artery. One option to relieve such a compression is an anterior aortopexy (AA). In this paper we describe our technique of an AA via a partial upper median sternotomy. Methods: A retrospective review of a prospectively maintained database of patients with IAS (July 2017 to November 2020) treated with AA via a partial upper median sternotomy at University teaching hospitals in the US was done. Results: Nine consecutive patients underwent AA for IAS during the study period. The median age was 9 months (IQR 3- 16.5). The male to female ratio was 1.25. All patients had $>70 \%$ compression by flexible bronchoscopy. 2 patients had previous surgeries. The follow-up was a median of 6 (IQR 4- 8.5) months. The indications for the operation were: reflex apnea (4/9 patients), recurrent intubation (4/9 patients), and severe stridor (1/9). IAS was a technical success (defined as [?] $20 \%$ residual stenosis) in $78 \%(7 / 9)$ of the patients. Complete symptom resolution after an AA was seen in $71 \%(5 / 7)$ of the patients. 2 patients had an unsuccessful AA, requiring a tracheal resection and an innominate artery reimplantation, respectively. Conclusion: An upper partial sternotomy approach provides a very versatile approach to an AA for IAS. Besides facilitating an adequate AA, it provides options for direct tracheal surgery or an innominate artery reimplantation in case an optimal result is not obtained by an AA.
\end{abstract}

Partial upper median sternotomy for anterior aortopexy for innominate artery compression syndrome: Our preferred technique.

Sandeep Sainathan ${ }^{1}$, MD and Raghav Murthy ${ }^{2}$, MD

1. Department of Surgery, Section of Pediatric cardiothoracic surgery,

University of Miami, Miami, FL

2. Department of Cardiothoracic surgery, Division of Pediatric cardiothoracic surgery,

Icahn School of Medicine of Mount Sinai, New York, NY

Corresponding Author:

Sandeep Sainathan, MD

$90 \mathrm{SW} 3^{\text {rd }}$ street

Apt 2006

Miami, FL 33130

Phone: 2034158115

Email: sainathans@outlook.com 
Key words: Innominate artery compression syndrome, aortopexy, partial sternotomy.

\begin{abstract}
:
Objectives: Innominate artery compression syndrome (IAS) is caused by an anterior compression of the trachea by an abnormally originating innominate artery. One option to relieve such a compression is an anterior aortopexy (AA). In this paper we describe our technique of an AA via a partial upper median sternotomy.
\end{abstract}

Methods : A retrospective review of a prospectively maintained database of patients with IAS (July 2017 to November 2020) treated with AA via a partial upper median sternotomy at University teaching hospitals in the US was done.

Results : Nine consecutive patients underwent AA for IAS during the study period. The median age was 9 months (IQR 3-16.5). The male to female ratio was 1.25 . All patients had $>70 \%$ compression by flexible bronchoscopy. 2 patients had previous surgeries. The follow-up was a median of 6 (IQR 4- 8.5) months. The indications for the operation were: reflex apnea (4/9 patients), recurrent intubation ( $4 / 9$ patients), and severe stridor (1/9). IAS was a technical success (defined as [?] $20 \%$ residual stenosis) in $78 \%(7 / 9)$ of the patients. Complete symptom resolution after an AA was seen in $71 \%(5 / 7)$ of the patients. 2 patients had an unsuccessful AA, requiring a tracheal resection and an innominate artery reimplantation, respectively.

Conclusion : An upper partial sternotomy approach provides a very versatile approach to an AA for IAS. Besides facilitating an adequate AA, it provides options for direct tracheal surgery or an innominate artery reimplantation in case an optimal result is not obtained by an AA.

Introduction: Anterior aortopexy (AA) for Innominate Artery compression Syndrome (IAS) was first described by Gross in 1948[1]. The procedure was performed by a left anterior thoracotomy. Since then, several approaches to perform an AA have been described such as a right thoracotomy, a median sternotomy, a partial upper sternotomy and even a thoracoscopic approach $[4,6]$. A partial upper sternotomy approach for AA for tracheomalacia from all causes has been previously described by Elliot [6]. This approach has become our preferred approach for an AA for IAS. In this paper, we illustrate our technique and describe the experience gained from 9 consecutive cases performed from 2018 to 2020 using an upper partial median sternotomy approach to an AA specifically for an IAS.

Methods: The study is a retrospective review of a prospectively maintained database of nine consecutive patients with IAS treated by AA from July 2017 to November 2020. The patients were operated by two surgeons at the University of Pittsburgh (SS- Sandeep Sainathan), University of Tennessee Health Sciences Center (SS), University of North Carolina at Chapel Hill (SS) and Mount Sinai Hospital in New York (RMRaghav Murthy). No other approach to an AA was attempted by the above surgeons to act as comparator. The study is a retrospective review of a prospectively maintained de-identified database. No further chartreview or any form of patient contact was attempted for this study and hence is IRB exempt. The study was not part of any research protocol and written informed consent was obtained for the operative procedures. No portions of the manuscript and the submitted pictures have any information that can lead to identification of the patient as per the Healthcare Insurance Portability and Accountability ACT of (HIPAA) 1996.

All the cases were referred either by pediatric cardiology or by pediatric pulmonology. Besides a detailed history and through physical exam, the work-up included an airway evaluation either with a flexible bronchoscopy or a rigid bronchoscopy (Figure 1 ) and a cross-sectional imaging either in the form of a computed tomography or MRI (Figure 2 ). The cases were discussed in a multidisciplinary case conference involving cardiac surgery, pediatric cardiology, pediatric pulmonology and pediatric otolaryngology. Surgery was offered when there was at least $70 \%$ tracheal stenosis at bronchoscopy from anterior tracheal compression by the innominate artery with associated symptoms. Technical success was defined [?]20\% residual stenosis after AA.

The data was abstracted for demographic information, clinical characteristics, operative intervention, complications and follow-up. Follow-up was the last documented clinic visit in the database. Given the sample 
size, only descriptive statistics were used.

Surgical Technique: The procedure is performed under general anesthesia with a single lumen endotracheal tube. A radial arterial line is used for hemodynamic monitoring. Venous access is generally peripheral. A flexible bronchoscopy is performed to assess the severity of the tracheal compression and also ensures that the endotracheal tube is positioned proximal to the area of the compression (Figure 1 ). It is critical to have an adequate extension of the neck with a shoulder roll in order to facilitate a partial upper sternotomy. This is particularly important in infants as they tend to have very short necks. The lower face, neck and the entire anterior chest is prepped and draped in a standard sterile fashion. Prophylactic antibiotics are used.

The procedure is started with a partial upper median sternotomy to the third intercostal space. A Diethrich sternal saw is used to divide the sternum after the suprasternal space is adequately developed by dividing the interclavicular ligament and bluntly dissecting the retrosternal space. Given the flexibility of the sternum in children, only a central split of the manubrium and the upper sternal body is necessary without any need for a $\mathrm{T}$ incision of the sternal body (Figure 3 ).

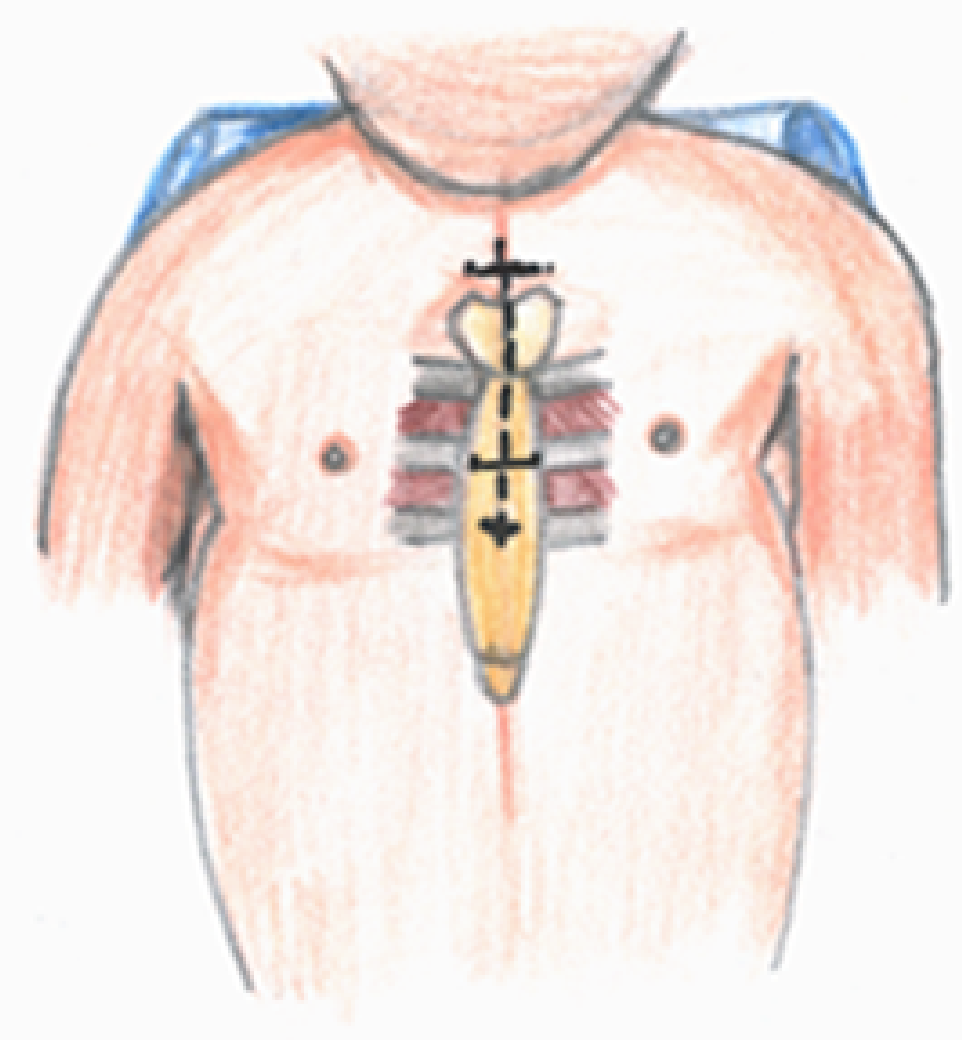

Figure 3 : Landmarks for an upper partial median sternotomy. The incision is carried through the midline of the sternum generally to the $2^{\text {nd }}$ intercostal space. Critical for exposure is an adequate extension of the neck with a good size shoulder roll, especially in infants.

A total thymectomy is then performed taking care not to injure the phrenic nerves bilaterally. This is critical as the thymus is often large and acts as a space occupying lesion. It is preferable not to enter the pleural spaces. The innominate vein is then mobilized and retracted superiorly. The innominate artery is then dissected only on its anterior aspect and the pericardial reflection at its base on the aortic arch is opened in a limited fashion. Again, it is critical not to circumferentially dissect the innominate artery as this will lead 
to a loss of the natural adhesion between it and the anterior surface of the trachea. A pretracheal plane is thus not developed. This is important. As the innominate artery is pulled anteriorly towards the sternum (given the space after the thymectomy), besides relieving the tracheal compression, it helps support the associated tracheomalacia by suspending the anterior wall of the trachea indirectly to the sternum (Figure 4 ).

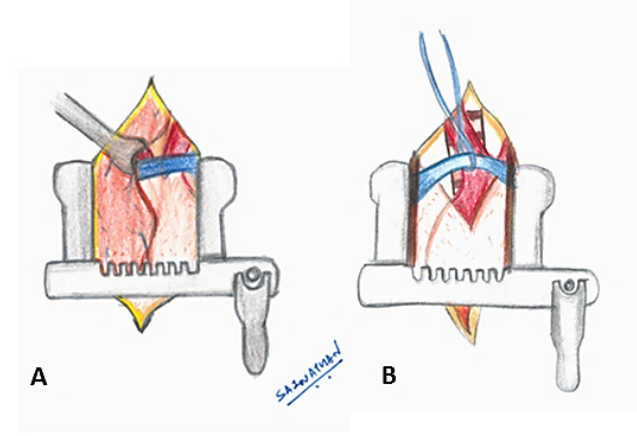

Figure 4: A : The left lobe of the thymus has been removed, exposing the innominate vein, the innominate artery, the left carotid artery and the proximal aortic arch covered by the pericardial investment. B : A full thymectomy is subsequently performed by removing the right lobe and is a key step as it increases the antero-superior mediastinal space. A limited superior pericardiotomy is performed to expose the junction of the innominate artery and the aortic arch. It is critical to not circumferentially dissect the innominate artery.

Typically, three sets of anchoring suture are required. The first set is placed at the junction middle and proximal thirds of the innominate artery, the second set is placed at the base of the innominate artery near the aortic arch and the third set is placed 0.5 to $1 \mathrm{~cm}$ below this on the anterior surface of the proximal aortic arch. At times, additional sutures may have to be placed distally and proximally to aforementioned sutures to optimize the result. This can be guided by pulling on the anterior surface of the innominate artery and the arch with real time flexible bronchoscopic exam to assess sites for suture placement (Figure 5 ). 


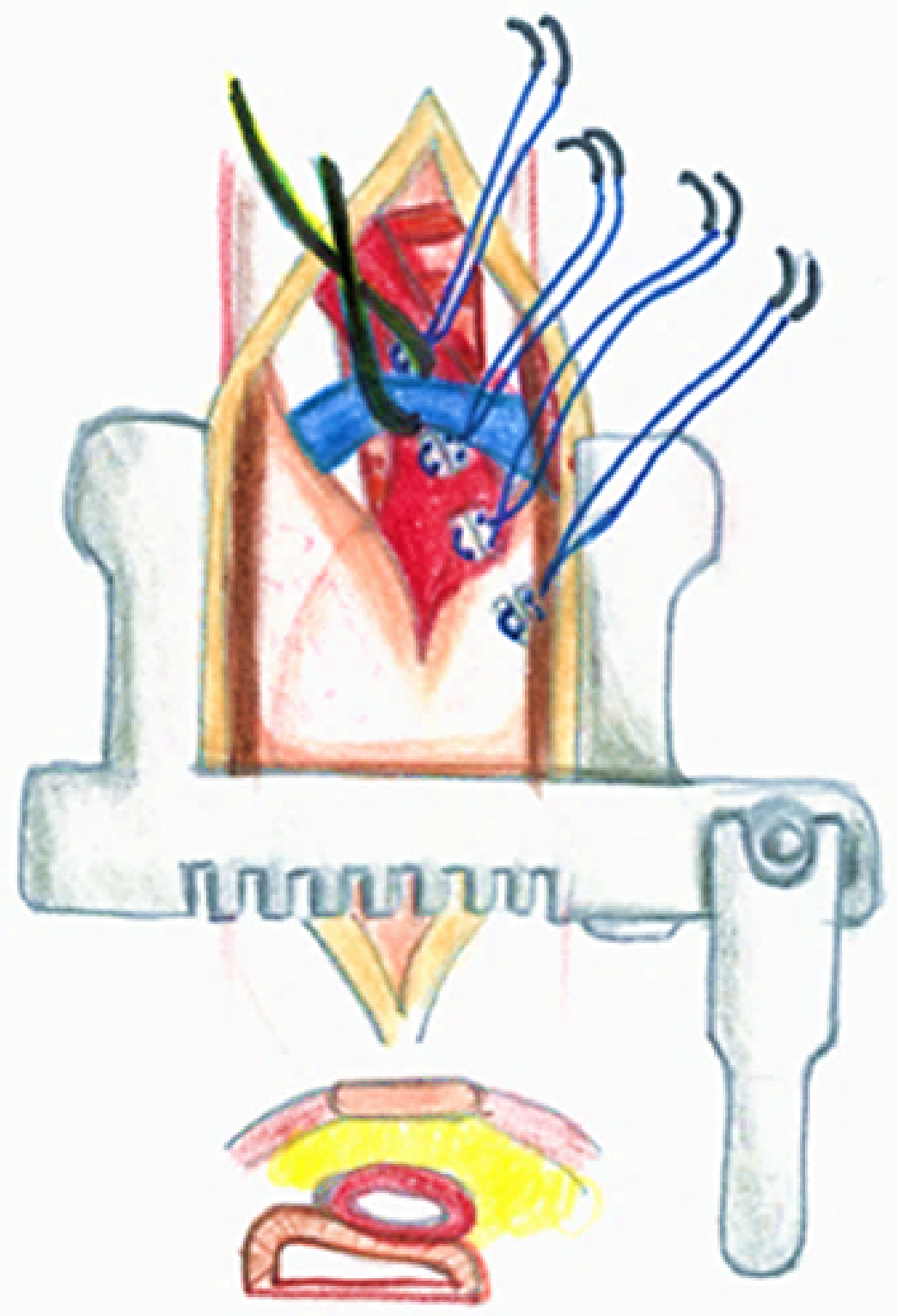




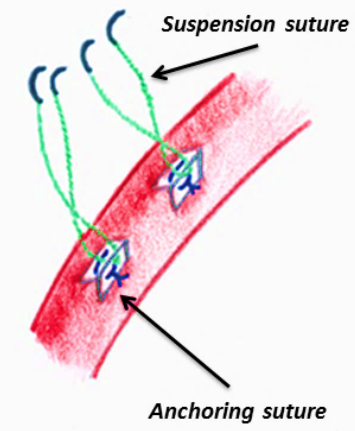

Figure 5: The pledgeted anchoringsutures on the innominate artery and proximal aortic arch shown. Using these anchoring sutures, the Ethibond suspensionsutures are then placed through them. The inset below shows the compression of the trachea by the innominate artery and presence of the thymus (yellow structure) acting as a space occupying structure in a cross-sectional view.

In order to get a good purchase on the artery, horizontal mattress felt pledgeted sutures with 5-0 Prolene sutures (Ethicon, Somerville, NJ) with either a BV-1 or a RB-2 needle are used on the artery in a partial thickness manner as the anchoring sutures. Using these felt pledget as anchors, 4-0 or 3-0 Ethibond® excel (Ethicon, Somerville, NJ) suspension sutures with a RB-1 needle are passed through the sternal table to pull the innominate artery anteriorly towards the posterior aspect of the sternal table. At, times when the sternal table is particularly thick as in an older child, a French eye needle with a larger gauge and size is used to facilitate the passage of the suture. The advantage of the this composite suture technique is use of a fine sutures such as a 5-0/ 6-0 Prolene suture with a fine needle supported with pledgets on the arterial structures as an anchoring sutures and the use of a more robust suture such as a 3-0/4-0 Ethibond suture with a stronger needle to pass through the full thickness of the sternal table as a suspension suture (Figure $\mathbf{5 , 6}$ ). Also, if the suspension sutures were to break during the securing process, a new suture can be easily replaced. For a left aortic arch, the left half of the sternal table is chosen and vice versa. Before tying down the Ethibond sutures on the anterior aspect of the sternal table, a mediastinal Blake@) drain (Ethicon, Somerville, NJ) is placed to drain the mediastinum. The tip of it is tucked into the pericardial space to drain it. The drain is exited retrosternally just below the xiphoid process (Figure $\mathbf{7}$ ). A set of about 2 to 3 sternal wires are placed. The sternal tables are partially bought together except for a $1 \mathrm{~cm}$ gap.

With real time flexible bronchoscopic guidance, the Ethibond@ excel sutures are cinched up and tied on the anterior aspect of the sternal table. Simultaneously, the innominate artery and the aortic arch can be observed gradually moving up towards the posterior aspect of the sternal table. The partial gap in the sternum helps with the visualization of any of the anchoring sutures cutting through the innominate artery or snapping of the suspension sutures as the sutures are tightened. The suture on the aortic arch is tightened first followed by the sutures distal to it as it is the most robust of the sutures. The innominate artery should rise up and should be well opposed to the posterior sternal table to optimize the AA. In one case, there was a cut through of the anchoring suture on the innominate artery requiring a revision. With all the sutures 
tightened and tied, the anterior compression on the trachea should be relieved and generally there is [?] $20 \%$ residual tracheal stenosis (Figure 6 ). If this result is not achieved, then alternate factors causing the compression need to be looked for. This can range from an innominate artery arising further leftward on a left aortic arch which cannot be sufficiently addressed just by an aortopexy or an intrinsic tracheal abnormality. In such cases, the partial sternotomy is converted to a full sternotomy to evaluate the anatomy further.

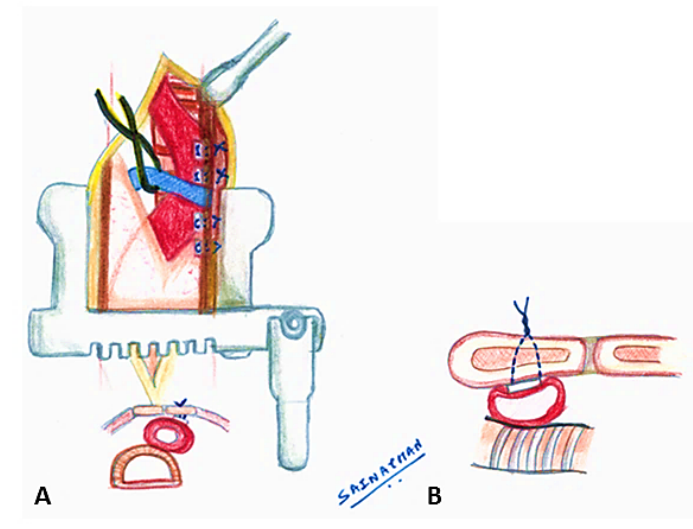

Figure 6 : A : The Ethibond suspension sutures have been passed through the left half of the sternal table and tied. Not shown are the sternal wires and the partial approximation of the sternum for clarity. The inset below shows the relief of the tracheal compression, anchoring of the innominate artery to the posterior aspect of the sternum and absence of the thymus in a cross-sectional view. B : Sagittal view after aortopexy showing the trans-sternal passage of suspension sutures and relief of the tracheal compression.

The partial sternotomy is closed in a standard fashion with steel wires for the partial sternotomy (Figure 7 ). The patients are typically extubated on the table. These patients are generally cared for in the ICU or the step down unit for the first 24 hours. A portable chest $\mathrm{x}$ ray is obtained to rule out any pneumothorax, assess the drain position and look for phrenic nerve palsy. Prophylactic antibiotics are used for 24 hours. 


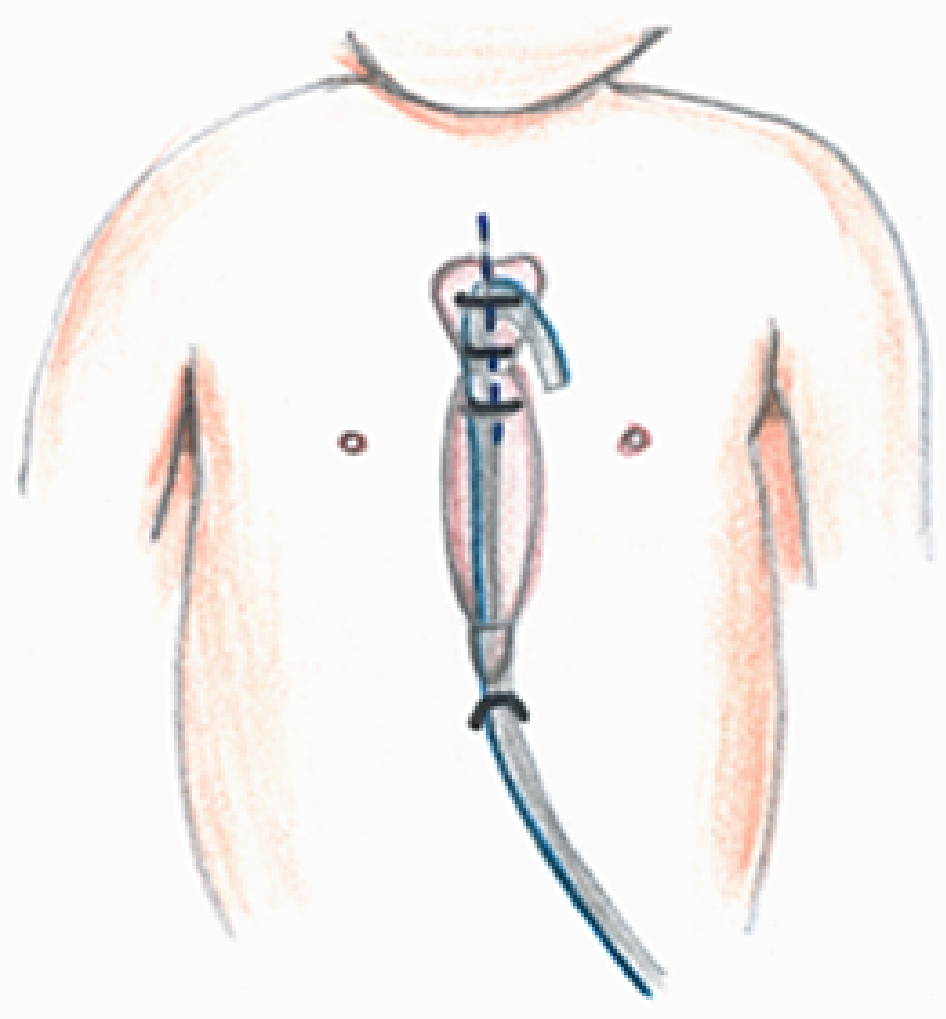

Figure 7 : Partial sternotomy incision after closure with a Blake drain draining the mediastinal and pericardial space and exiting inferior to the xiphoid process.

Results: A total of 9 patients underwent AA for IAS from 2017 to 2020 (Table 1). The median age was 9 months (IQR 3- 16.5). The male to female ratio was 1.25 (5/4 patients). The aortic arch was left sided in $89 \%$ (8/9) patients. 2 patients had chromosomal abnormalities (one each with Trisomy 21 and 18). All patients had $>70 \%$ compression by flexible bronchoscopy. 2 patients had previous surgeries. One patient had a double aortic arch with an atretic left arch which was divided previously via left thoracotomy and the other patient had a trachea-esophageal fistula which was previously repaired via right thoracotomy. The followup was a median of 6 (IQR 4- 8.5) months. The indications for the operation were: reflex apnea 44\% (4/9 patients), recurrent intubation $44 \%$ (4/9 patients), and severe stridor $11 \%(1 / 9)$. IAS was a technical success (defined [?] 20\% residual stenosis) in $78 \%$ of the patients (7/9 patients). Complete symptom resolution after an AA was seen $71 \%$ of the patients (5/7 patients) with technical success. Of the two patients who had incomplete symptom resolution despite a technical success, one patient had a $20 \%$ residual stenosis with mild 
stridor but has not had any further episodes of reflex apnea. The other patient with $15 \%$ residual stenosis had mild residual stridor but also had an associated glottic pathology. AA was unsuccessful in 2 patients with an initial attempted procedure producing $50 \%$ residual stenosis. One patient had an associated intrinsic tracheal stenosis from isolated tracheal cartilage deficiency which was not diagnosed preoperatively and was treated with a tracheal resection and anastomosis using cardiopulmonary bypass. The other patient had an innominate artery arising very leftward along the aortic arch and needed a re-implantation of the innominate artery rightward of the trachea in a more normal position. Interestingly, this patient also had a right sided upper partial anomalous pulmonary venous return needing a Warden repair. Both had an excellent result after the above described procedures. There were no wound infections, phrenic nerve palsy, pericardial or pleural effusion in the patients. One patient needed a repeat full sternotomy 6 months after the AA to repair a complete atrioventricular canal defect at 8 months of age.

\begin{tabular}{|c|c|c|c|c|c|c|c|c|}
\hline & $\begin{array}{l}\text { Age/ } \\
\text { Gender }\end{array}$ & Symptoms & Comorbidity & $\begin{array}{l}\text { Aortic } \\
\text { sidedness }\end{array}$ & Severity & $\begin{array}{l}\text { Surgical } \\
\text { technique }\end{array}$ & $\begin{array}{l}\text { Technical } \\
\text { result }\end{array}$ & $\begin{array}{l}\text { Other } \\
\text { procedures }\end{array}$ \\
\hline 1 & $4 \mathrm{mo} / \mathrm{M}$ & $\begin{array}{l}\text { Noisy } \\
\text { breathing, } \\
\text { respira- } \\
\text { tory } \\
\text { distress }\end{array}$ & None & LAA & $\begin{array}{l}75 \% \text { distal } \\
\text { tracheal } \\
\text { compression }\end{array}$ & $\begin{array}{l}\text { Thymectomy } \\
\text { Anterior } \\
\text { aortopexy }\end{array}$ & $\begin{array}{l}10 \% \\
\text { residual } \\
\text { tracheal } \\
\text { stenosis }\end{array}$ & \\
\hline 2 & $2 \mathrm{mo} / \mathrm{M}$ & $\begin{array}{l}\text { Respiratory } \\
\text { failure, } \\
\text { Recurrent } \\
\text { intubation }\end{array}$ & $\begin{array}{l}\text { Downs } \\
\text { syndrome } \\
\text { CAVCD } \\
\text { Prune } \\
\text { Belly }\end{array}$ & LAA & $\begin{array}{l}80 \% \text { distal } \\
\text { tracheal } \\
\text { compression }\end{array}$ & $\begin{array}{l}\text { Thymectomy } \\
\text { Anterior } \\
\text { aortopexy }\end{array}$ & $\begin{array}{l}10 \% \\
\text { residual } \\
\text { tracheal } \\
\text { stenosis }\end{array}$ & $\begin{array}{l}\text { Redo ster- } \\
\text { notomy, } \\
\text { CAVCD } \\
\text { repair at } 8 \\
\text { months of } \\
\text { age }\end{array}$ \\
\hline 3 & $9 \mathrm{mo} / \mathrm{M}$ & $\begin{array}{l}\text { Recurrent } \\
\text { death } \\
\text { spells }\end{array}$ & T 18 & LAA & $\begin{array}{l}80 \% \text { distal } \\
\text { tracheal } \\
\text { compression }\end{array}$ & $\begin{array}{l}\text { Thymectomy } \\
\text { Anterior } \\
\text { aortopexy }\end{array}$ & $\begin{array}{l}5 \% \\
\text { residual } \\
\text { tracheal } \\
\text { stenosis }\end{array}$ & \\
\hline 4 & $2 \mathrm{mo} / \mathrm{F}$ & $\begin{array}{l}\text { Recurrent } \\
\text { failure of } \\
\text { extubation }\end{array}$ & $\begin{array}{l}\text { Prematurity } \\
\text { Partial } \\
\text { anomalous } \\
\text { pulmonary } \\
\text { venous } \\
\text { return, } \\
\text { PDA }\end{array}$ & LAA & $\begin{array}{l}90 \% \text { distal } \\
\text { tracheal } \\
\text { compression }\end{array}$ & $\begin{array}{l}\text { Thymectomy } \\
\text { Anterior } \\
\text { aortopexy }\end{array}$ & $\begin{array}{l}50 \% \\
\text { tracheal } \\
\text { stenosis }\end{array}$ & $\begin{array}{l}\text { Translocatio } \\
\text { of innomi- } \\
\text { nate } \\
\text { artery } \\
\text { Warden } \\
\text { repair of } \\
\text { PAPVR, } \\
\text { PDA } \\
\text { ligation }\end{array}$ \\
\hline 5 & $16 \mathrm{mo} / \mathrm{F}$ & $\begin{array}{l}\text { Noisy } \\
\text { breathing, } \\
\text { respira- } \\
\text { tory } \\
\text { distress }\end{array}$ & None & LAA & $\begin{array}{l}80 \% \text { distal } \\
\text { tracheal } \\
\text { compres- } \\
\text { sion Mild } \\
\text { posterior } \\
\text { membrane } \\
\text { intrusion }\end{array}$ & $\begin{array}{l}\text { Thymectomy } \\
\text { Anterior } \\
\text { aortopexy }\end{array}$ & $\begin{array}{l}20 \% \\
\text { residual } \\
\text { tracheal } \\
\text { stenosis }\end{array}$ & \\
\hline
\end{tabular}




\begin{tabular}{|c|c|c|c|c|c|c|c|c|}
\hline & $\begin{array}{l}\text { Age/ } \\
\text { Gender }\end{array}$ & Symptoms & Comorbidity & $\begin{array}{l}\text { Aortic } \\
\text { sidedness }\end{array}$ & Severity & $\begin{array}{l}\text { Surgical } \\
\text { technique }\end{array}$ & $\begin{array}{l}\text { Technical } \\
\text { result }\end{array}$ & $\begin{array}{l}\text { Other } \\
\text { procedures }\end{array}$ \\
\hline 6 & $10 \mathrm{mo} / \mathrm{M}$ & $\begin{array}{l}\text { Noisy } \\
\text { breathing, } \\
\text { respira- } \\
\text { tory } \\
\text { distress }\end{array}$ & None & LAA & $\begin{array}{l}80 \% \text { distal } \\
\text { tracheal } \\
\text { compression }\end{array}$ & $\begin{array}{l}\text { Thymectomy } \\
\text { Anterior } \\
\text { aortopexy }\end{array}$ & $\begin{array}{l}5 \% \\
\text { residual } \\
\text { tracheal } \\
\text { stenosis }\end{array}$ & \\
\hline 7 & $2 \mathrm{mo} / \mathrm{F}$ & $\begin{array}{l}\text { Recurrent } \\
\text { failure of } \\
\text { extubation }\end{array}$ & Prematurity & LAA & $\begin{array}{l}90 \% \text { distal } \\
\text { tracheal } \\
\text { stenosis }\end{array}$ & $\begin{array}{l}\text { Thymectomy } \\
\text { Anterior } \\
\text { aortopexy }\end{array}$ & $\begin{array}{l}50 \% \\
\text { tracheal } \\
\text { stenosis }\end{array}$ & $\begin{array}{l}\text { Full ster- } \\
\text { notomy, } \\
\text { CPB, } \\
\text { tracheal } \\
\text { resection } \\
\text { and } \\
\text { anastomosis }\end{array}$ \\
\hline 8 & $24 \mathrm{mo} / \mathrm{M}$ & $\begin{array}{l}\text { Recurrent } \\
\text { failure of } \\
\text { extubation }\end{array}$ & $\begin{array}{l}\text { Tracheostomy } \\
\text { Prior } \\
\text { complete } \\
\text { vascular } \\
\text { ring } \\
\text { division } \\
\text { Multiple } \\
\text { vocal cord } \\
\text { surgeries }\end{array}$ & yRAA & $\begin{array}{l}80 \% \text { right } \\
\text { lateral } \\
\text { distal } \\
\text { tracheal } \\
\text { compression }\end{array}$ & $\begin{array}{l}\text { Thymectomy } \\
\text { Anterior } \\
\text { aortopexy } \\
\text { (Right } \\
\text { sternal } \\
\text { table) }\end{array}$ & $\begin{array}{l}15 \% \\
\text { residual } \\
\text { tracheal } \\
\text { stenosis }\end{array}$ & $\begin{array}{l}\text { Off } \\
\text { ventilator, } \\
\text { with } \\
\text { tracheostomy }\end{array}$ \\
\hline 9 & $17 \mathrm{mo} / \mathrm{F}$ & $\begin{array}{l}\text { Severe } \\
\text { stridor }\end{array}$ & $\begin{array}{l}\text { Prematurity, } \\
\text { TEF, s/p } \\
\text { TEF } \\
\text { repair via } \\
\text { right } \\
\text { thoracotomy }\end{array}$ & LAA & $\begin{array}{l}75 \% \text { distal } \\
\text { tracheal } \\
\text { stenosis }\end{array}$ & $\begin{array}{l}\text { Thymectomy } \\
\text { Anterior } \\
\text { aortopexy }\end{array}$ & $\begin{array}{l}10 \% \\
\text { residual } \\
\text { tracheal } \\
\text { stenosis }\end{array}$ & \\
\hline
\end{tabular}

Table 1 : Demographics, clinical presentation, and operative procedure (LAA/ RAA: Left/Right aortic arch, CAVCD: Complete atrioventricular canal defect, PAPVR: Partial anomalous venous return, PDA: Patent ductus arteriosus, TEF: Tracheo-esophageal fistula, CPB: Cardiopulmonary bypass).

Discussion : AA for IAS was first described by Gross in 1948[1]. The patient was a 4 month-old female infant who had recurrent episodes of severe respiratory distress and respiratory tract infections. The AA was performed through a left anterior thoracotomy approach. After a partial thymectomy, an abnormal leftward arising innominate artery was fixed to the retrosterum. The operation was successful with complete relief of the symptoms. Since then, various approaches to AA have been described such a left or right thoracotomy, a thoracoscopic approach, a full median sternotomy and a partial upper median sternotomy [4,6]. Our preferred technique is the partial upper median sternotomy.

IAS is thought to be due to an abnormal innominate artery arising distally along the aortic arch and hence crossing the trachea anteriorly from a left to right direction. This leads to a potential for a compressive effect and is further facilitated by overcrowding of the upper mediastinum due to the presence of a large thymus especially in the younger children $[5,7]$.

Common symptoms include stridor, reflex apnea (a sudden respiratory arrest cause by an irritation of the area of compression), and recurrent respiratory tract infections. It can also present as failure to wean from mechanical ventilation. Stridor by itself is not an indication. Strong indication for surgery are reflex apnea, two or more episodes of infection, severe compression ( $>70 \%$ luminal reduction), and dependence on 
mechanical ventilation. Of these, reflex apnea is the strongest indication for an intervention as it can lead to mortality $[2,3]$.

IAS is diagnosed by flexible bronchoscopy, which shows an anterior pulsatile compression in the distal trachea. Besides this, a flexible bronchoscopy facilitates the conduct of the AA operation. It helps determine the number and position of the anchoring sutures and helps evaluate the result of the AA by assessing the degree of resolution of IAS (Figure $\mathbf{1}$ ). Cross-sectional imaging such as a CT angiogram or an MRI is obtained to further evaluate the anatomy (Figure $\mathbf{2}$ ).

A partial upper median sternotomy approach to an AA for tracheomalcia from various causes has been previously described by Elliot [6]. In this paper, we describe our technique for AAselectively for IAS. This has become our preferred approach for the following reasons. Firstly, it facilitates the performance of a complete thymectomy. The bilateral phrenic nerves are better visualized and thus at a lesser risk for injury. A complete thymectomy is central to the success of the operation as it increases the available anteroposterior dimension in the upper mediastinum as often these children have a large thymus gland. Without a thymectomy, the degree to which the innominate artery moves towards the sternum is limited and thus the distracting force on the trachea. Secondly, the goal is to get a good anatomic result by accepting only a [?]20\% residual stenosis after an AA. This was evident in our study as the patients who did not achieve a technical success needed an alternative procedure. If this not achieved, one needs to look for alternative factors such as an intrinsic tracheal pathology. A partial sternotomy approach facilitates this as it is easy to convert to a full sternotomy and explore the anterior surface of the trachea between the SVC and the aorta as compared to a thoracotomy approach. In one case, the patient had an intrinsic tracheal stenosis due to isolated tracheal cartilage deficiency which was not diagnosed preoperatively and required a tracheal resection and has been previously published by us [8]. Thirdly, the anatomy of the innominate artery is better appreciated by this approach. Alternative to an AA to treat IAS is an innominate artery reimplantation procedure. As previously described, the innominate artery in IAS arises further leftward along the aortic arch. Hence, it crosses anterior to the trachea from a left to right direction compressing it anteriorly. The innominate artery can be reimplanted in an off- pump manner by re-implanting the artery 1 $\mathrm{cm}$ proximal on the greater curvature of the aorta rightward of the trachea $[5,7]$.Such an reimplantation has an immediate effect of relieving the compression with no long-term consequence [5]. Only one patient needed this approach in this series after a test AA failed to produce an optimal result. Again, a midline approach as compared to the thoracotomy approach greatly facilitated this operation as this approach requires a median sternotomy. Fourthly, a full sternotomy is unnecessary as the operative procedure is limited to the upper mediastinum and an upper partial sternotomy actually facilitates when a future re-sternotomy is needed arises as described next.

AA by an upper partial median sternotomy does not preclude a repeat sternotomy if certain precautions are taken. In an infant with Down syndrome, prune belly syndrome, complete atrioventricular canal defect and recurrent failure to wean from mechanical ventilation, an AA was performed at age 2 months and a complete repair of the canal defect was performed at age 8 months. The patient did well after the aortopexy and was liberated from mechanical ventilation. At redo sternotomy, because the lower pericardium and the sternum were intact after the initial surgery, an easy retrosternal plane could be established and the posterior sternal table in the region of the aortopexy was divided under direct vision by deviating rightwards of it. The repair was intact and did not interfere with the canal repair. As previously described, if the aortic arch is left sided, then the innominate artery is fixed to the left half of the sternal table, distracting it away from the trachea in an anterior and leftward fashion and if the aortic arch is right sided, the aortopexy is done to the right half of the sternotomy. This also helps with a future redosterntomy as the innominate artery is not fixed across the sternotomy incision.

It is critical not to develop a pretacheal plane and we believe is another key step for a successful AA. By dissecting the innominate artery circumferentially away from the trachea, the compressive effect will be relieved. However, if severe tracheomalcia is present, it will lead to collapse of the anterior wall of the trachea. Pulling the innominate artery anteriorly, besides producing a distracting compression relieving effect on the 
trachea, has an additional suspensory effect. This was evident in the original description by Gross [1] where a residual tracheal stenosis was seen due to underlying tracheomalacia due to such as circumferential dissection of the artery.

The composite suture technique simplifies the operation. While fine sutures are used on the artery, heavy sutures are used for the AA. If the suspension sutures were to snap, they can be easily replaced before the sternum is closed.

The strengths of the study are the description of the technical pearls and pitfalls for a successful AA via an upper partial sternotomy as evidenced by the good operative outcomes. The limitations are the small sample size, absence of a comparator such as another technique for an AA and lack of long-term follow up.

Conclusion : An upper partial sternotomy approach provides a very versatile approach to an AA for IAS. Besides facilitating an adequate AA, it provides options for direct tracheal surgery or an innominate artery reimplantation in case an optimal result is not obtained by an AA.

Funding Source : None

Conflict of Interest : None

Ethics Statement : The study is a retrospective review of a prospectively maintained de-identified database. No further chart-review or any form of patient contact was attempted for this study and hence is IRB exempt. The study was not part of any research protocol and written informed consent was obtained for the operative procedures. No portions of the manuscript and the submitted pictures have any information that can lead to identification of the patient as per the Healthcare Insurance Portability and Accountability ACT of (HIPAA) 1996.

\section{References:}

1. Gross RE, Neuhauser EB. Compression of the trachea by an anomalous innominate artery; an operation for its relief. Am J Dis Child. 1948 Apr; 75(4):570-4.

2. Moës CA, Izukawa T, Trusler GA. Innominate artery compression of the Trachea. Arch Otolaryngol. 1975 Dec; 101(12):733-8.

3. Fearon B, Shortreed R. Tracheobronchial compression by congenital cardiovascular anomalies in children with syndrome of apnea. Ann Otol Rhinol laryngol. 1963 Dec; 72:949-69.

4. Torre M, Carlucci M, Speggiorin S, Elliott MJ. Aortopexy for the treatment of tracheomalacia in children: review of the literature. Ital J Pediatr. 2012 Oct 30; 38:62.

5. Grimmer JF, Herway S, Hawkins JA, Park AH, Kouretas PC. Long-term results of innominate artery reimplantation for tracheal compression. Arch Otolaryngol Head Neck Surg. 2009 Jan; 135(1):80-4.

6. Anterior Aortopexy for Tracheomalacia Elliott M.J., Speggiorin S., Torre M. (2011) Operative Techniques in Thoracic and Cardiovascular Surgery, 16 (4), pp. 309-321.

7. Hawkins JA, Bailey WW, Clark SM. Innominate artery compression of the trachea. Treatment by reimplantation of the innominate artery. J Thorac Cardiovasc Surg. 1992 Apr; 103(4):678-82.

8. Sainathan S, Sharma M. Median Sternotomy for Innominate Artery Compression Syndrome and Distal Tracheal Stenosis. Am Surg. 2021 Feb 26:3134821998675. 


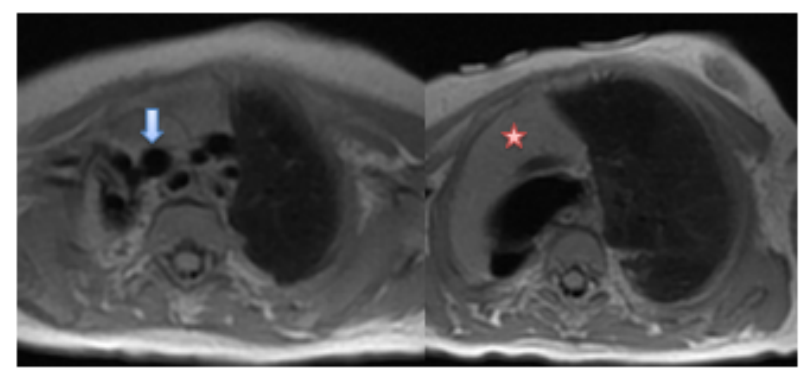

Figure 1: A transverse section MRI scan of the chest showing the innominate artery (arrow) in close apposition to the trachea and causing compression. Also, note the large thymus (star) in the anterosuperior mediastinum causing crowding.

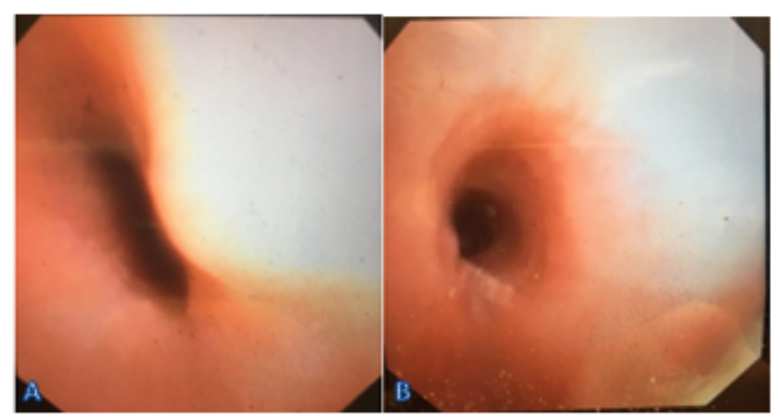

Figure 2 : Flexible bronchoscopy showing: A : anterior extramural compression of the trachea by the innominate artery causing $>70 \%$ reduction if the luminal area, B : 5\% residual tracheal luminal area after a successful AA 